\title{
Clinical Outcomes of Asynchronous Versus Synchronous Telepsychiatry in Primary Care: Randomized Controlled Trial
}

Peter M Yellowlees ${ }^{1}$, MBBS, MD; Michelle Burke Parish ${ }^{1}$, MA, PhD; Alvaro D Gonzalez ${ }^{1}$, MA; Steven R Chan ${ }^{2,3}$, MBA, MD; Donald M Hilty ${ }^{4}$, MD; Byung-Kwang Yoo ${ }^{5}$ PhD, MD; J Paul Leigh ${ }^{5}$, PhD; Robert M McCarron ${ }^{6}$, DO; Lorin M Scher ${ }^{1}$, MD; Andres F Sciolla ${ }^{1}$, MD; Jay Shore ${ }^{7}$, MD; Glen Xiong ${ }^{1}$, MD; Katherine M Soltero ${ }^{8}$, LCSW; Alice Fisher ${ }^{5}$, BA; Jeffrey R Fine ${ }^{5}$, MPH; Jennifer Bannister ${ }^{1}$, EdM; Ana-Maria Iosif ${ }^{5}$, PhD

\footnotetext{
${ }^{1}$ Department of Psychiatry and Behavioral Sciences, University of California Davis, Sacramento, CA, United States

${ }^{2}$ Stanford University School of Medicine, Stanford, CA, United States

${ }^{3}$ Veterans Administration Palo Alto Healthcare System, Palo Alto, CA, United States

${ }^{4}$ Northern California Veterans Administration, Mather, CA, United States

${ }^{5}$ Department of Public Health Sciences, University of California Davis, Davis, CA, United States

${ }^{6}$ University of California Irvine, Irvine, CA, United States

${ }^{7}$ University of Colorado Anschutz Medical Campus, Denver, CO, United States

${ }^{8}$ CommuniCare Health Centers, West Sacramento, Sacramento, CA, United States
}

\section{Corresponding Author:}

Peter M Yellowlees, MBBS, MD

Department of Psychiatry and Behavioral Sciences

University of California Davis

Sacramento, CA

United States

Phone: 19167340849

Email: pmyellowlees@ucdavis.edu

\section{Abstract}

Background: Asynchronous telepsychiatry (ATP; delayed-time) consultations are a novel form of psychiatric consultation in primary care settings. Longitudinal studies comparing clinical outcomes for ATP with synchronous telepsychiatry (STP) are lacking.

Objective: This study aims to determine the effectiveness of ATP in improving clinical outcomes in English- and Spanish-speaking primary care patients compared with STP, the telepsychiatry usual care method.

Methods: Overall, 36 primary care physicians from 3 primary care clinics referred a heterogeneous sample of 401 treatment-seeking adult patients with nonurgent psychiatric disorders. A total of 184 (94 ATP and 90 STP) English- and Spanish-speaking participants (36/184, 19.6\% Hispanic) were enrolled and randomized, and 160 (80 ATP and 80 STP) of them completed baseline evaluations. Patients were treated by their primary care physicians using a collaborative care model in consultation with the University of California Davis Health telepsychiatrists, who consulted with patients every 6 months for up to 2 years using ATP or STP. Primary outcomes (the clinician-rated Clinical Global Impressions [CGI] scale and the Global Assessment of Functioning [GAF]) and secondary outcomes (patients' self-reported physical and mental health and depression) outcomes were assessed every 6 months.

Results: For clinician-rated primary outcomes, ATP did not promote greater improvement than STP at 6-month follow-up (ATP vs STP, adjusted difference in follow-up at 6 months vs baseline differences for CGI: $0.2,95 \% \mathrm{CI}-0.2$ to $0.6 ; P=.28$; and GAF: $-0.6,95 \% \mathrm{CI}-3.1$ to $1.9 ; P=.66$ ) or 12 -month follow-up (ATP vs STP, adjusted difference in follow-up at 12 months vs baseline differences for CGI: $0.4,95 \% \mathrm{CI}-0.04$ to $0.8 ; P=.07$; and GAF: $-0.5,95 \% \mathrm{CI}-3.3$ to $2.2 ; P=.70$ ), but patients in both arms had statistically and clinically significant improvements in both outcomes. There were no significant differences in improvement from baseline between ATP and STP on any patient self-reported ratings at any follow-up (all $P$ values were between .17 and .96). Dropout rates were higher than predicted but similar between the 2 arms. Of those with baseline visits, 46.8\% (75/160) did not have a follow-up at 1 year, and $72.7 \%$ (107/147) did not have a follow-up at 2 years. No serious adverse events were associated with the intervention. 
Conclusions: This is the first longitudinal study to demonstrate that ATP can improve clinical outcomes in English- and Spanish-speaking primary care patients. Although we did not find evidence that ATP is superior to STP in improving clinical outcomes, it is potentially a key part of stepped mental health interventions available in primary care. ATP presents a possible solution to the workforce shortage of psychiatrists and a strategy for improving existing systems of care.

Trial Registration: ClinicalTrials.gov NCT02084979; https://clinicaltrials.gov/ct2/show/NCT02084979.

(J Med Internet Res 2021;23(7):e24047) doi: $10.2196 / 24047$

\section{KEYWORDS}

asynchronous telepsychiatry; synchronous telepsychiatry; psychiatrist; primary care physician; psychiatric consultation; Spanish-speaking; collaborative care; workforce; depression; telehealth

\section{Introduction}

\section{Background}

Telepsychiatry, in the form of videoconferencing, is now an important tool in behavioral health care. For more than 30 years, synchronous telepsychiatry (STP), where consultations are performed in real time and are interactive, has increased access to care, making psychiatric experts available in areas with provider shortages. Research has demonstrated high levels of patient satisfaction and similar clinical outcomes to traditional in-person care for many disorders, including depression and anxiety [1,2]. Telemedicine utilization across all disciplines had already been anticipated to grow exponentially to a 130 billion dollar industry by 2025 [3], before the use of telepsychiatry dramatically increased during the COVID-19 pandemic. Suddenly, telepsychiatry has become a core health care tool [4] for most psychiatrists in the United States. Many clinics rapidly converted to telepsychiatry, with a number of them describing the experience and the changes required including the move to in-home consultations or virtual house calls. For example, the large University of California Davis (UCD) behavioral health outpatient clinic saw a successful conversion from approximately $97 \%$ in-person consultations to $100 \%$ virtual consultations in 3 days [4]. A survey conducted by the American Psychiatric Association during the COVID-19 pandemic found that by June $2020,85 \%$ of 500 surveyed American psychiatrists were using telepsychiatry with more than $75 \%$ of their patients, compared with about 3\% before COVID-19 [5]. The latest available national telehealth statistics derived from 60 contributing private insurers to the Fair Health database [6] as of December 2020 showed an increase of $2816 \%$ in telehealth consultations in all disciplines compared with December 2019, and these comprised $6.5 \%$ of all consultations nationally in their database, with $47 \%$ of the patients being seen primarily for mental health reasons [6]. The National Center for Health Statistics [7] reported a total of 883 million outpatient consultations nationally in 2018. Projecting from the insurance statistics [6], we can assume that about $3 \%$ of these visits in 2020 were telepsychiatry visits (by video or phone), an approximate total of 26 million such visits. There seems no doubt that STP has now become a major delivery component of mental health services in the United States.

\section{Asynchronous Care}

Despite this success, with STP being the current standard telepsychiatry practice $[8,9]$, administrative and technical challenges exist, especially around scheduling of telepsychiatrists and patients [10,11], and STP itself is simply a virtual extension of in-person care that cannot be scaled to enable a physician to see more patients. Asynchronous care makes use of a completely virtual care model with the transmission of clinical information via web applications for review by a specialist at a later time $[12,13]$ and has the potential to scale and enable psychiatrists to be involved in the treatment of more patients than with STP. Asynchronous care can also reduce the impact of poor bandwidth and connectivity issues seen with STP, providing potentially better access to more diverse patient populations. In recent years, asynchronous technologies have become more widespread in health care settings, utilized in patient portal email and messaging, in-app messaging, specialty patient-to-provider mobile apps, and forwarded interview videos [14]. Asynchronous technologies are commonly used in radiology, dermatology, ophthalmology, cardiology, and pathology [12,15-22] and are expanding into mental health care where they may be at least a partial solution to address the psychiatrist workforce shortage and reduce access barriers for patients [14]. Studies indicate that up to $10 \%$ of those who reported experiencing mental health difficulties are able to utilize available asynchronous resources [23], which can improve self-management and access. Positive patient outcomes have been demonstrated with e-coaching for depression [24], mobile-based asynchronous text-messaging therapy with a licensed therapist [25], integrated asynchronous virtual care platform [26], and asynchronous telehealth [27]. In addition to improved patient outcomes, such services have been found to increase access and care quality and reduce overutilization and costs of care [26].

Asynchronous telepsychiatry (ATP) is a more data-rich form of the traditional medical or psychiatric curbside consultation. In ATP, a trained interviewer conducts and records a semistructured patient interview, which is combined with other available clinical data, such as electronic medical records (EMRs). This recorded video consult and information from the EMR is made accessible to a telepsychiatrist who reviews it before providing an opinion on the patient's diagnosis and treatment options. The process, including consultation templates, has been fully described in previous publications [8,28-33]. Early pilot studies provide evidence that ATP has similar diagnostic accuracy to STP in English- and Spanish-speaking patients, that it is a feasible consultation modality in primary care patients and with patients cared for in skilled nursing 
facilities [28-35], and that it may also be less costly to implement.

\section{Objectives}

This paper describes the first large study conducted to determine the effectiveness of ATP in improving clinical outcomes, as compared with STP, the current gold standard telepsychiatry usual care treatment method. We hypothesized that, compared with participants in the STP arm, participants in the ATP arm would show better clinical trajectories throughout treatment, as measured by greater improvements in clinician and patient self-reported ratings of global functioning, health outcomes, and depression.

\section{Methods}

\section{Study Design and Setting}

The study was a randomized controlled clinical trial conducted at 3 community-based primary care clinics in the Sacramento area, with patient recruitment occurring between March 2014 and September 2018. A data and safety monitoring board (DSMB), consisting of 2 independent physicians and 1 statistician, periodically reviewed and evaluated the accumulated study data for participant safety, study conduct, and progress. In a DSMB review in early 2018, it was noted that the dropout rate at 24 months was higher than anticipated. Thus, the DSMB recommended that the primary end point be at 12 months and advised subsequent enrollment be limited to the 12-month follow-up. The 12-month follow-up was the primary analysis of interest, and the institutional review board (IRB) documentation was modified in April 2018. The last 18 patients were enrolled for 1 year.

\section{Participants}

We recruited 36 primary care physicians (PCPs) as referring providers. We placed an alert in the electronic medical record system to remind the PCPs about the trial. Patients learned about the study through their PCP or from advertisements at the referring clinics. All participants were aged 18 years or older, able to give written informed consent, and were referred by PCPs as having one or more nonurgent mental health diagnoses, mainly mood disorders, anxiety disorders, or substance and alcohol use disorders. Many patients had comorbid conditions and multiple diagnoses. We attempted to overenroll Spanish-speaking patients and included a Federally Qualified Health Center that primarily treats Spanish-speaking patients as one of our referring clinics. The study protocol was approved by the UCD IRB; written informed consent was obtained from both patients and the referring PCPs before participation.

Potential participants completed a multistep screening and enrollment process. This consisted of a semistructured phone interview as well as the Patient Health Questionnaire-9 (PHQ-9) [36] to screen for risk of suicidality, followed by an in-person assessment with the Structured Clinical Interview for the Diagnostic Statistical Manual (SCID) IV Diagnoses in English or Spanish [37]. The SCID established a primary axis I diagnosis, which was used for stratified randomization. Before enrolling the first participant, the study statistician created a stratified block randomization schedule for each study site.
Within each site, patients were assigned 1:1 to the 2 intervention arms in random permuted blocks of size 4 generated for each SCID primary axis I categorization to reduce imbalance between arms.

Patients were recruited for 4 study years and were followed up between 1 and 2 years with ATP or STP evaluations every 6 months (up to 5 visits). Four UCD faculty psychiatrists provided consultations for both ATP and STP groups, with a bilingual psychiatrist seeing all the patients who could only speak Spanish or preferred to have their consultations in that language. All psychiatrists were fully trained to deliver both types of consultations. Diagnostic conclusions and treatment recommendations of the consulting psychiatrist for all patients were reported back to the PCP in the psychiatrists' notes in the EMR. The PCPs then implemented the recommendations at their own discretion and could also communicate further by secure messaging or phone with the psychiatrists if they wished. ATP interviewers in the trial were behavioral health clinicians with a master's degree or higher, and their training for this trial has already been described [38].

\section{Intervention Arm}

ATP assessments were conducted at 6-month intervals by an ATP-trained clinician who spoke the patient's primary language, either English or Spanish [38]. This interview was video-recorded using Health Insurance Portability and Accountability Act-compliant security systems and protocols. For each ATP assessment, the clinician updated a standardized electronic form to capture notes about clinically relevant or important materials observed during the interview. These notes were usually completed the day of the ATP interview so that study psychiatrists had rapid access to the entire interview video, the clinician's interview notes, and previous medical and sometimes psychiatric assessments of the patient already recorded in their EMR. After each ATP visit, the psychiatrist provided the patient's PCP with a written assessment and psychiatric treatment plan. The PCP also had continued access to this psychiatrist by phone or email between the study consultations for up to 2 years $[8,38]$.

\section{Control Arm}

The clinical workflow process for the STP arm was similar to that of the ATP arm, except that ATP-recorded assessments were replaced by live real-time STP assessments conducted by a psychiatrist who spoke the patient's preferred language, either English or Spanish. After the STP consultation, the psychiatrist provided the patient's PCP with a written assessment and treatment plan in the patient's EMR and was available for future contact by phone or email as necessary.

A demographic questionnaire was administered at the baseline to collect sociodemographic information. Participants were clinically assessed in both study arms at 6-month intervals (baseline, 6 months, 12 months, 18 months, and 24 months), with the primary outcome measures completed by the treating psychiatrists. All other study questionnaires assessing self-reported outcomes were collected every 6 months by research assistants either by phone or via paper or electronic surveys, depending on participants' preferences. Participants 
were compensated for each assessment visit with a US \$25 gift card, an amount considered by the IRB to be noncoercive. The PCPs were not compensated.

\section{Primary Outcomes}

The primary outcomes were derived from the psychiatrist's report and included the Clinical Global Impressions (CGIs) scale [39], which focuses primarily on functional impairment, and the Global Assessment of Functioning (GAF) [40], which mainly measures symptom severity. The CGI is a 3-item, 7-point observer-rated scale that measures illness severity, global improvement or change, and therapeutic response. The CGI is considered a robust measure with established validity in inpatient [41], outpatient [42], and clinical trial settings [42]. The CGI severity of illness and improvement scales are commonly used in nondrug trial settings [39]. We used the CGI severity of illness scale scored from 1 (normal) to 7 (among the most extremely ill). The GAF is a widely used rating scale for assessing impairment among patients with psychiatric disorders. The GAF assesses the level of psychological, social, and occupational functioning on a scale of 1 to 100, with higher levels indicating better functioning [40].

\section{Secondary Outcomes}

Secondary outcomes focused on patient self-report and included the 12-Item Short-Form Health Survey Physical Health Summary (PHS-12) and 12-Item Short-Form Health Survey Mental Health Summary (MHS-12) [43] scores (both scored from 0-100, with higher scores indicating better health) and the PHQ-9 [44]. The PHQ-9 is a well-validated depression scale with scores derived as the sum of 9 items (each scored from 0 [not at all] to 3 [nearly every day]; scale range 0-27) based directly on the diagnostic criteria for major depressive disorder in the Diagnostic and Statistical Manual Fourth Edition [37].

\section{Sample Size Calculation}

The statistical power to assess the difference in improvement from baseline to the primary end point (12 months) between ATP and STP for the clinician and patient-reported measures was evaluated assuming that 100 patients would be randomized into each arm, an attrition rate of $25 \%$, and that half an SD was the smallest difference that would be clinically meaningful. Assuming a type 1 error $\alpha=.05$, a two-sided test, measurements at baseline, 6 , and 12 months, correlations between repeated measures ranging from 0.30 to 0.60 , and the proposed sample size of 75 patients in each arm (after $25 \%$ loss to follow-up), we anticipated having $83 \%-96 \%$ power to detect half an SD difference in improvement between the arms at 12 months. On the basis of published data, we estimated a residual SD of 1.5 for CGI [45] and 10-12 points for the mental (MHS-12) and physical health (PHS-12) subscales of the 12-Item Short-Form Health Survey [46]. Thus, under the above assumptions, this study was sufficiently powered to detect a difference in improvement between the arms at 12 months of 0.75 for CGI and 5-6 points on MHS-12 and PHS-12. The calculation assumes 75 patients per arm, but some of the patients lost to follow-up would have completed some evaluations and contributed data, and thus the power would be higher. In addition, the power would be higher if the correlation between repeated measures was greater than 0.6 .

\section{Statistical Analysis}

Group differences in demographic and clinical characteristics were assessed using $\chi^{2}$ test (or Fisher exact test) for categorical variables and the two-sample (two-tailed) $t$ tests (or Wilcoxon two-sample test) for continuous variables, as appropriate.

All analyses were intention-to-treat, and patients were analyzed as randomized. Mixed-effects linear regression models [47] were used to characterize the longitudinal trajectories of primary and secondary outcomes and assess intervention effects. This approach explicitly accounts for multiple measurements per person, allows for unequally spaced and missing observations, and produces valid inferences under the assumption that data are missing at random. The primary end point was the 12-month follow-up, and all participants who had at least 1 follow-up clinician rating at 6 or 12 months were included in the primary analysis. For each outcome variable, we fit a model that included terms for the intervention arm (ATP or STP), time (baseline, 6 months, and 12 months), and the interaction between arm and time. Models for clinician-rated outcomes were adjusted for a composite variable whose levels captured all possible combinations of study sites, treating psychiatrists, and language of the interview. Models for patient self-reported outcomes were similarly adjusted for a composite variable whose levels captured all possible combinations of study site, person conducting the interview (ATP interviewer or STP psychiatrist), and language of the interview. We accounted for clustering using a random effect for the patient and, whenever possible, a random effect for the referring physician. The interaction terms allowed us to assess intervention effects, that is, adjusted differences in follow-up compared with baseline differences between ATP and STP. All contrasts were estimated with 95\% CIs and tested with two-sided alternatives using $P<.05$ as a threshold for statistical significance. No adjustments were made for multiple comparisons. Secondary analyses to confirm the longitudinal pattern from the primary analyses were conducted using the data up to 24 months and included all participants with at least 1 follow-up visit. Sensitivity analyses controlling for baseline values were conducted to confirm the primary analysis results. All analyses were performed using PROC MIXED in SAS version 9.4 (SAS Institute Inc) [48].

\section{Results}

\section{Overview}

Of the 36 consented clinicians, 28 (78\%) referred at least one patient. Figure 1 depicts the flow of patients from screening through the primary end point and the 12-month follow-up. Of the 401 patients assessed for eligibility, 184 (45.9\%) were enrolled and randomized to the ATP $(n=94)$ or STP $(n=90)$ intervention. Of the 184 randomized participants, 18 (9.8\%; 11 ATP and 7 STP) consented to the 12-month follow-up, and 24 (13\%; 14 ATP and 10 STP) withdrew before the baseline visit. Reasons for withdrawal before baseline included insurance changes $(n=2)$, decline to participate $(n=7)$, and loss to follow-up $(n=15)$. Multimedia Appendix 1, Table S1 shows the 
demographic and clinical characteristics of the 160 participants who completed the baseline visit and the 24 who did not. The 2 groups were similar in terms of sociodemographic characteristics and depression symptoms, but participants who completed the baseline visit were more likely to be receiving current outpatient psychotherapy for a psychiatric condition
$(65 / 158,41.1 \%$ vs $5 / 24,21 \% ; P=.06)$ and to be using psychotropic medication $(130 / 157,82.8 \%$ vs $12 / 24,50 \%$; $P<.001)$ than those who did not complete baseline visits. Interestingly, only 1 of these 160 patients who completed a baseline visit was seeing an outpatient psychiatrist, with the rest being treated in primary care.

Figure 1. Participants flow through 12-month follow-up. ATP: asynchronous telepsychiatry; STP: synchronous telepsychiatry.

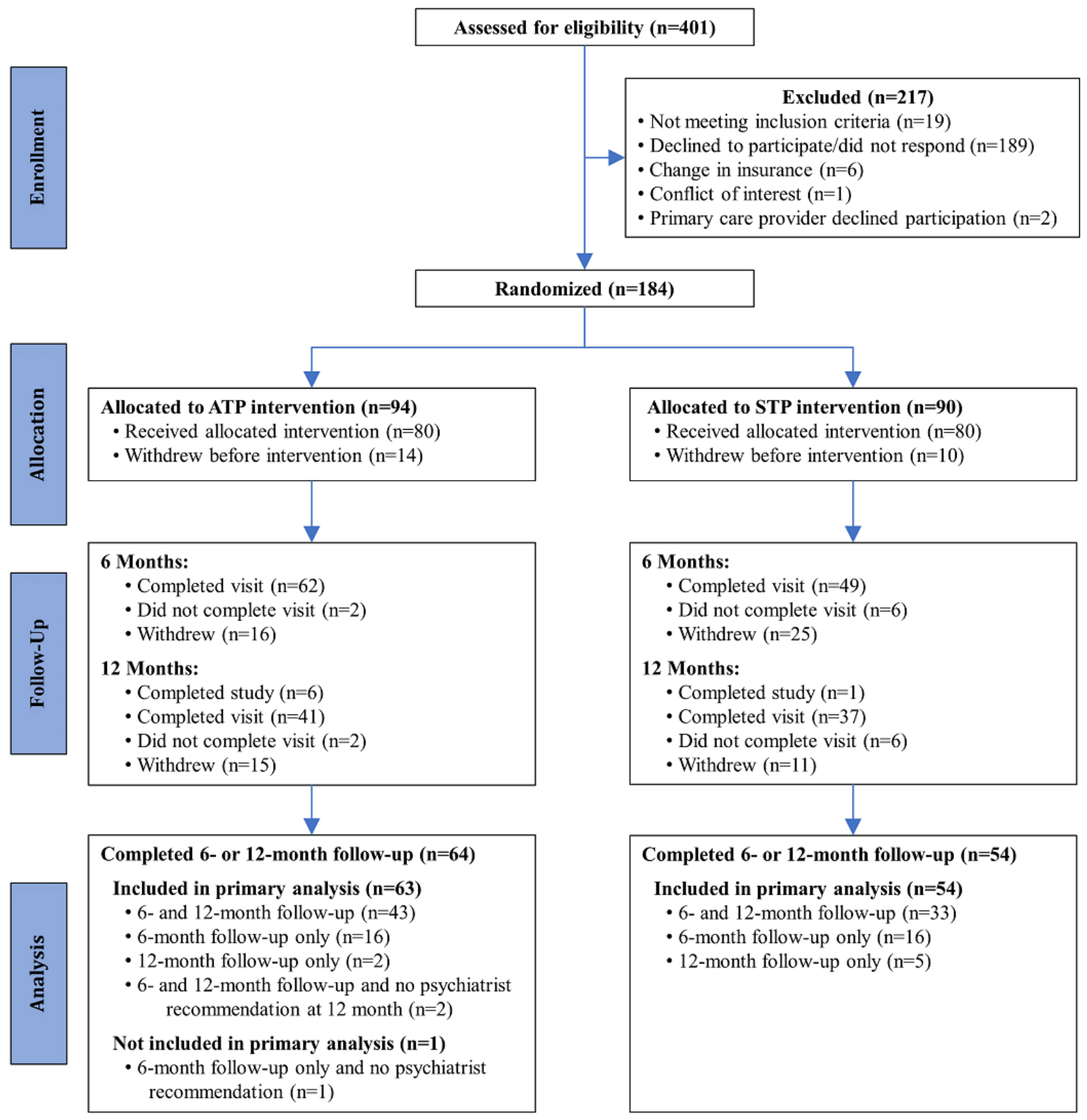

Figure S1 in Multimedia Appendix 1 depicts the flow of patients from screening through the last assessment of the study (24-month follow-up). The dropout rates were higher than originally anticipated. From baseline to the end of the study, $64 \%(51 / 80)$ patients in the ATP arm and 78\% (62/80) patients in the STP arm did not complete the study as enrolled (ie, for 12 or 24 months). In the ATP group, 9\% (7/80) of the participants had insurance changes, $23 \%$ (18/80) declined to continue, $31 \%$ (25/80) were lost to follow-up, and 1 did not complete the study because of an administrative scheduling error. In the STP group, 14\% (11/80) had insurance changes, $18 \%(14 / 80)$ declined to continue, $43 \%$ (34/80) were lost to follow-up, 1 participant was too ill to continue the study, and 2 participants died. There was no association between arm assignment and the reasons for not completing the study $(P=.33)$.

Baseline demographic and clinical characteristics by study arm are presented in Table 1. There were no significant arm 
differences in any of these characteristics, indicating that the randomization was effective. Of the 160 participants, 137 $(85.6 \%)$ were White and $30(18.8 \%)$ were Hispanic. Most patients (54 ATP, 54 STP, ie, 67\% for each arm) had depressive disorders as their primary diagnosis. Of the 160 patients with baseline data, $117(73.1 \%)$ completed follow-up at 6 months or 12 months and had usable primary outcome data (CGI or GAF) for at least 1 follow-up and were included in the primary analyses (Figure 1). Multimedia Appendix 1, Table S2 compares the demographic and clinical characteristics of the participants who completed the baseline visit and were included $(n=117)$ or excluded $(n=43)$ from the primary analyses. Participants excluded from the primary analyses were more likely to have been patients in the Auburn clinic and had lower CGI scores and higher GAF scores at baseline (Multimedia Appendix 1, Table S2). 
Table 1. Baseline demographic and clinical characteristics of participants who completed baseline visits ${ }^{\mathrm{a}}$.

\begin{tabular}{|c|c|c|c|}
\hline Characteristics ${ }^{\mathrm{b}}$ & $\operatorname{ATP}^{c}(n=80)$ & $\operatorname{STP}^{\mathrm{d}}(\mathrm{n}=80)$ & Total $(n=160)$ \\
\hline Age (years), mean (SD) & $53(14)$ & $52.2(14.6)$ & $52.6(14.3)$ \\
\hline Number of axis I diagnoses, mean (SD) & $2.4(1)$ & $2.4(1)$ & $2.4(1)$ \\
\hline Screening PHQ- $9^{\mathrm{e}}$ score $^{\mathrm{f}, \mathrm{g}}$, mean (SD) & $13.9(6.6)$ & $13.1(5.9)$ & $13.5(6.3)$ \\
\hline \multicolumn{4}{|l|}{ Screening PHQ-9 category ${ }^{\mathrm{g}}$, n (\%) } \\
\hline $0-4$, nondepressed & $5(6.3)$ & $8(10.3)$ & $13(8.3)$ \\
\hline 5-9, mild depression & $18(22.8)$ & $16(20.5)$ & $34(21.7)$ \\
\hline 10-14, moderate depression & $21(26.6)$ & $23(29.5)$ & $44(28)$ \\
\hline$\geq 15$, moderately severe to severe depression & $35(44.3)$ & $31(39.7)$ & $66(42)$ \\
\hline \multicolumn{4}{|l|}{ Primary diagnosis, $\mathbf{n}(\%)$} \\
\hline Mood disorder & $54(67.5)$ & $54(67.5)$ & $108(67.5)$ \\
\hline Anxiety disorder & $16(20)$ & $16(20)$ & $32(20)$ \\
\hline Substance abuse & $2(2.5)$ & $1(1.3)$ & $3(1.9)$ \\
\hline Other & $8(10)$ & $9(11.3)$ & $17(10.6)$ \\
\hline Female, n (\%) & $58(72.5)$ & $53(66.3)$ & $111(69.4)$ \\
\hline Hispanic ethnicity, n (\%) & $15(18.8)$ & $15(18.8)$ & $30(18.8)$ \\
\hline \multicolumn{4}{|l|}{ Education, $\mathbf{n}(\%)$} \\
\hline Graduate high school or less & $22(27.5)$ & $18(22.5)$ & $40(25)$ \\
\hline Some college or 2-year college & $32(40)$ & $40(50)$ & $72(45)$ \\
\hline College or graduate school & $26(32.5)$ & $22(27.5)$ & $48(30)$ \\
\hline \multicolumn{4}{|l|}{ Marital status $^{\mathbf{h}}, \mathbf{n}(\%)$} \\
\hline Married or living with someone & $39(51.3)$ & $39(52.7)$ & $78(52)$ \\
\hline Other $^{\mathrm{i}}$ & $37(48.7)$ & $35(47.3)$ & $72(48)$ \\
\hline Current psychiatric treatment ${ }^{\mathrm{j}}, \mathrm{n}(\%)$ & $31(39.7)$ & $34(42.5)$ & $65(41.1)$ \\
\hline Current psychotropic medication ${ }^{\mathrm{k}}, \mathrm{n}(\%)$ & $64(83.1)$ & $66(82.5)$ & $130(82.8)$ \\
\hline \multicolumn{4}{|l|}{ Language of the interview, $n(\%)$} \\
\hline English & $71(88.8)$ & $70(87.5)$ & $141(88.1)$ \\
\hline Spanish & $9(11.3)$ & $10(12.5)$ & $19(11.9)$ \\
\hline \multicolumn{4}{|l|}{ Study clinic, n (\%) } \\
\hline Auburn & $44(55)$ & $43(53.8)$ & $87(54.4)$ \\
\hline J Street (Sacramento) & $17(21.3)$ & $19(23.8)$ & $36(22.5)$ \\
\hline Communicare & $19(23.8)$ & $18(22.5)$ & $37(23.1)$ \\
\hline
\end{tabular}

${ }^{\mathrm{a}}$ Due to rounding, percentages might not sum to 100 .

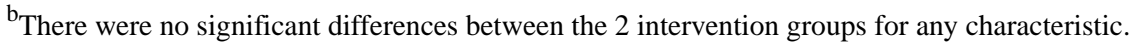

${ }^{\mathrm{c}}$ ATP: asynchronous telepsychiatry.

${ }^{\mathrm{d}}$ STP: synchronous telepsychiatry.

${ }^{\mathrm{e}}$ PHQ-9: Patient Health Questionnaire-9.

${ }^{\mathrm{f}}$ Range 0-27, higher is more depressed.

${ }^{\mathrm{g}}$ Data missing $=1$ in asynchronous telepsychiatry group and 2 in synchronous telepsychiatry.

${ }^{\mathrm{h}}$ Data missing $=4$ in asynchronous telepsychiatry group and 6 in synchronous telepsychiatry.

${ }^{\mathrm{i}}$ Includes widowed, divorced or annulled, separated, and never married.

${ }^{\mathrm{j}}$ Data missing $=2$ in asynchronous telepsychiatry group.

${ }^{\mathrm{k}}$ Data missing=3 in asynchronous telepsychiatry group. 


\section{Primary Outcomes}

Table 2 summarizes the mean trajectories and changes from baseline in the 2 intervention arms for the clinician ratings (CGI and GAF) and the results of mixed-effects models for the primary analysis. For both CGI and GAF, ATP did not promote greater improvement than STP at the 6- (ATP vs STP, adjusted difference in follow-up at 6 months vs baseline differences for CGI: $0.2,95 \% \mathrm{CI}-0.2$ to $0.6 ; P=.28$; and GAF: $-0.6,95 \% \mathrm{CI}$ -3.1 to $1.9 ; P=.66$ ) or 12 -month follow-up (ATP vs STP, adjusted difference in follow-up at 12 months vs baseline differences for CGI: $0.4,95 \%$ CI -0.04 to $0.8 ; P=.07$; and GAF: $-0.5,95 \%$ CI -3.3 to $2.2 ; P=.70$ ). However, both the ATP and STP arms improved at 6 and 12 months compared with baseline.
Patients in both arms had about 1 point improvement in CGI at 6-month follow-up (estimated difference from baseline -0.7 , $95 \% \mathrm{CI}-1.0$ to $-0.4 ; P<.001$ for ATP; and $-0.9,95 \% \mathrm{CI}-1.2$ to $-0.6 ; P<.001$ for STP), and these improvements were maintained at 12 months (estimated difference from baseline $-0.8,95 \% \mathrm{CI}-1.1$ to $-0.5 ; P<.001$ for ATP; and $-1.2,95 \% \mathrm{CI}$ -1.5 to $-0.9 ; P<.001$ for STP). The results for GAF were similar, with both groups improving by about 3 points at 6-month (estimated difference from baseline $2.7,95 \%$ CI $1.1-4.4 ; P=.002$ for ATP; and 3.3, 95\% CI 1.4-5.1; $P<.001$ for STP) and by about 5 points at 12-month follow-up (estimated difference from baseline 4.7, 95\% CI 2.8-6.5; $P<.001$ for ATP; and 5.2, $95 \%$ CI 3.2-7.2; $P<.001$ for STP).

Table 2. Primary outcomes: clinician ratings at baseline and 6- and 12-month follow-up for the 117 patients included in the primary analysis.

\begin{tabular}{|c|c|c|c|c|c|}
\hline Primary outcomes & Patient, n (\%) & $\begin{array}{l}\mathrm{CGI}^{\mathrm{a}} \text {, mean } \\
(\mathrm{SD})\end{array}$ & $\begin{array}{l}\mathrm{GAF}^{\mathrm{b}} \text {, mean } \\
\text { (SD) }\end{array}$ & $\begin{array}{l}\text { CGI; estimate, mean } \\
(95 \% \mathrm{CI})^{\mathrm{c}}\end{array}$ & $\begin{array}{l}\text { GAF; estimate, mean } \\
(95 \% \mathrm{CI})^{\mathrm{c}}\end{array}$ \\
\hline \multicolumn{6}{|l|}{$\mathbf{A T P}^{\mathbf{d}}$} \\
\hline \multicolumn{6}{|l|}{ Mean trajectory } \\
\hline Baseline & $63(100)$ & $3.9(0.9)$ & $59.7(10.8)$ & $\mathrm{e}^{\mathrm{e}}$ & - \\
\hline Follow-up at 6 months & $61(97)$ & $3.2(1)$ & $62.4(11.9)$ & - & - \\
\hline Follow-up at 12 months & $45(71)$ & $3.1(1.1)$ & $63.7(13)$ & - & - \\
\hline \multicolumn{6}{|l|}{ Change from baseline } \\
\hline 6 months versus baseline & $61(97)$ & $-0.7(1)$ & $2.8(6.3)$ & $-0.7(-1.0$ to -0.4$)$ & 2.7 (1.1 to 4.4$)$ \\
\hline 12 months versus baseline & $45(71)$ & $-0.8(1.2)$ & $4.4(8.7)$ & $-0.8(-1.1$ to -0.5$)$ & 4.7 (2.8 to 6.5$)$ \\
\hline \multicolumn{6}{|l|}{$\operatorname{STP}^{\mathbf{f}}$} \\
\hline \multicolumn{6}{|l|}{ Mean trajectory } \\
\hline Baseline & $54(100)$ & $4.2(1)$ & $57.6(10.2)$ & - & - \\
\hline Follow-up at 6 months & $49(91)$ & $3.3(1)$ & $60.7(11.0)$ & - & - \\
\hline Follow-up at 12 months & $38(70)$ & $3.0(1)$ & $61.8(12.2)$ & - & - \\
\hline \multicolumn{6}{|l|}{ Change from baseline } \\
\hline 6 months versus baseline & $49(91)$ & $-0.9(1)$ & $2.9(6.4)$ & $-0.9(-1.2$ to -0.6$)$ & $3.3(1.4$ to 5.1$)$ \\
\hline 12 months versus baseline & $38(70)$ & $-1.2(1)$ & $5.1(6.3)$ & $-1.2(-1.5$ to -0.9$)$ & $5.2(3.2$ to 7.2$)$ \\
\hline ATP versus STP, difference at baseline & - & - & - & $-0.3(-0.6$ to 0.1$)$ & $0.9(-2.1$ to 4$)$ \\
\hline ATP versus STP, difference at follow-up at 6 months & - & - & - & $-0.1(-0.4$ to 0.3$)$ & $0.4(-2.8$ to 3.5$)$ \\
\hline $\begin{array}{l}\text { ATP versus STP, difference at follow-up at } 12 \\
\text { months }\end{array}$ & - & - & - & $0.1(-0.3$ to 0.5$)$ & $0.4(-2.9$ to 3.7$)$ \\
\hline $\begin{array}{l}\text { ATP versus STP, difference in follow-up at } 6 \text { months } \\
\text { versus baseline differences }\end{array}$ & - & - & - & $0.2(-0.2$ to 0.6$)$ & $-0.6(-3.1$ to 1.9$)$ \\
\hline $\begin{array}{l}\text { ATP versus STP, difference in follow-up at } 12 \\
\text { months versus baseline differences }\end{array}$ & - & - & - & $0.4(-0.04$ to 0.8$)$ & $-0.5(-3.3$ to 2.2$)$ \\
\hline
\end{tabular}

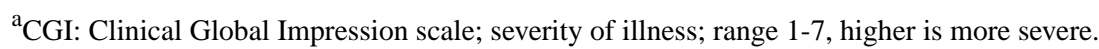

${ }^{\mathrm{b}} \mathrm{GAF}$ : Global Assessment of Functioning; range 0-100, higher is better functioning.

${ }^{\mathrm{c}}$ From mixed-effects linear regression models adjusted for study site, consulting psychiatrist, and language of the interview, as well as clustering due to patient. The model for the Global Assessment of Functioning was further adjusted for clustering by the referring physician.

${ }^{\mathrm{d}}$ ATP: asynchronous telepsychiatry.

${ }^{\mathrm{e}}$ Not available.

${ }^{\text {f }}$ TP: synchronous telepsychiatry. 


\section{Secondary Outcomes}

Tables 3 and 4 show the descriptive statistics and the results of mixed-effects models for patient self-reported ratings: PHS-12, MHS-12, and PHQ-9, respectively. The pattern of the self-reported ratings was less consistent throughout the follow-up for both ATP and STP arms, with only the mental health score in STP showing statistically significant improvement at 6 months and the PHQ-9 score showing improvement in the ATP group at both 6 and 12 months. However, there were no statistically significant differences in improvement between the intervention arms at any time point for any patient self-reported ratings.

Table 3. Secondary outcomes: patient self-reported 12-Item Short-Form Health Survey (physical and mental) scores at baseline and 6- and 12-month follow-up for the 117 patients included in the primary analysis.

\begin{tabular}{|c|c|c|c|c|c|}
\hline Secondary outcomes & Patient, n (\%) & $\begin{array}{l}\text { PHS-12 } \\
\text { mean }(S D)\end{array}$ & $\begin{array}{l}\text { MHS- } 12^{\mathrm{b}}, \\
\text { mean }(\mathrm{SD})\end{array}$ & $\begin{array}{l}\text { PHS-12; estimate, } \\
\text { mean }(95 \% \mathrm{CI})^{\mathrm{c}}\end{array}$ & $\begin{array}{l}\text { MHS-12; estimate, } \\
\text { mean }(95 \% \mathrm{CI})^{\mathrm{c}}\end{array}$ \\
\hline \multicolumn{6}{|l|}{$\mathbf{A T P}^{\mathbf{d}}$} \\
\hline \multicolumn{6}{|l|}{ Mean trajectory } \\
\hline Baseline & $52(83)$ & $39.6(11.6)$ & $34.4(9.6)$ & $\mathrm{E}^{\mathrm{e}}$ & - \\
\hline Follow-up at 6 months & $51(81)$ & $39.5(11.5)$ & $36.7(9.8)$ & - & - \\
\hline Follow-up at 12 months & $42(67)$ & $38.7(11.5)$ & $38.2(9.1)$ & - & - \\
\hline \multicolumn{6}{|l|}{ Change from baseline } \\
\hline 6 months versus baseline & $43(68)$ & $-1.4(8.8)$ & $2(11.9)$ & $-1.2(-3.9$ to 11.61 .6$)$ & $2.5(-0.7$ to 5.7$)$ \\
\hline 12 months versus baseline & $33(52)$ & $0.3(9.3)$ & $3.7(12.5)$ & 0.1 ( -3.0 to 3.2$)$ & $3.6(-0.003$ to 7.1$)$ \\
\hline \multicolumn{6}{|l|}{$\mathbf{S T P}^{\mathbf{f}}$} \\
\hline \multicolumn{6}{|l|}{ Mean trajectory } \\
\hline Baseline & $45(83)$ & $43.4(10.4)$ & $31.7(8.9)$ & - & - \\
\hline Follow-up at 6 months & $41(76)$ & $41.3(10.5)$ & $36(11.1)$ & - & - \\
\hline Follow-up at 12 months & $28(52)$ & $43.9(9.4)$ & $34.3(10.4)$ & - & - \\
\hline \multicolumn{6}{|l|}{ Change from baseline } \\
\hline 6 months versus baseline & $34(63)$ & $-1.8(11.4)$ & $5.1(10.4)$ & $-2.1(-5$ to 0.8$)$ & $4.7(1.4$ to 8.1$)$ \\
\hline 12 months versus baseline & $24(44)$ & $-1.1(8.9)$ & $5(9.9)$ & 0.001 ( -3.3 to 3.3$)$ & $3.7(-0.2$ to 7.5$)$ \\
\hline ATP versus STP, difference at baseline & - & - & - & $-9.5(-32.5$ to 13.6$)$ & $-2.7(-24.1$ to 18.8$)$ \\
\hline $\begin{array}{l}\text { ATP versus STP, difference at follow-up at } 6 \\
\text { months }\end{array}$ & - & - & - & $-8.6(-31.5$ to 14.4$)$ & $-4.9(-26.1$ to 16.3$)$ \\
\hline $\begin{array}{l}\text { ATP versus STP, difference at follow-up at } 12 \\
\text { months }\end{array}$ & - & - & - & $-9.4(-32.5$ to 13.8$)$ & $-2.8(-24.4$ to 18.8$)$ \\
\hline $\begin{array}{l}\text { ATP versus STP, difference in follow-up at } 6 \\
\text { months versus baseline differences }\end{array}$ & - & - & - & $0.9(-3.1$ to 4.9$)$ & $-2.2(-6.9$ to 2.5$)$ \\
\hline $\begin{array}{l}\text { ATP versus STP, difference in follow-up at } 12 \\
\text { months versus baseline differences }\end{array}$ & - & - & - & $0.1(-4.4$ to 4.7$)$ & $-0.1(-5.3$ to 5.1$)$ \\
\hline
\end{tabular}

${ }^{a}$ PHS-12: 12-Item Short-Form Health Survey Physical Health Summary; range 0-100, higher is better physical health.

${ }^{b}$ MHS-12: 12-Item Short-Form Health Survey Mental Health Summary; range 0-100, higher is better mental health.

${ }^{c}$ From mixed-effects linear regression models adjusted for study site, consulting psychiatrist, and language of the interview as well as clustering due to patient and primary care physician.

${ }^{\mathrm{d}}$ ATP: asynchronous telepsychiatry.

e Not available.

${ }^{\text {f }}$ TP: synchronous telepsychiatry. 
Table 4. Secondary outcomes: patient self-reported Patient Health Questionnaire-9 scores at baseline and 6- and 12-month follow-up for the 117 patients included in the primary analysis.

\begin{tabular}{|c|c|c|c|}
\hline Secondary outcomes & Patient, n (\%) & PHQ-9 ${ }^{\mathrm{a}}$, mean $(\mathrm{SD})$ & PHQ-9; estimate, mean $(95 \% \mathrm{CI})^{\mathrm{b}}$ \\
\hline \multicolumn{4}{|l|}{$\mathbf{A T P}^{\mathbf{c}}$} \\
\hline \multicolumn{4}{|l|}{ Mean trajectory } \\
\hline Baseline & $61(97)$ & $12.4(7.2)$ & $-^{\mathrm{d}}$ \\
\hline Follow-up at 6 months & $57(90)$ & $9.8(6.7)$ & - \\
\hline Follow-up at 12 months & $45(71)$ & $10(6)$ & - \\
\hline \multicolumn{4}{|l|}{ Change from baseline } \\
\hline 6 months versus baseline & $55(87)$ & $-2.3(4.4)$ & $-2.4(-3.8$ to -0.9$)$ \\
\hline 12 months versus baseline & $43(68)$ & $-2.8(5.2)$ & $-2.2(-3.9$ to -0.5$)$ \\
\hline \multicolumn{4}{|l|}{$\operatorname{STP}^{\mathrm{e}}$} \\
\hline \multicolumn{4}{|l|}{ Mean trajectory } \\
\hline Baseline & $53(98)$ & $12.6(6.8)$ & - \\
\hline Follow-up at 6 months & $40(74)$ & $10.8(6.5)$ & - \\
\hline Follow-up at 12 months & $34(63)$ & $11.9(7.1)$ & - \\
\hline \multicolumn{4}{|l|}{ Change from baseline } \\
\hline 6 months versus baseline & $40(74)$ & $-0.7(4.8)$ & $-0.9(-2.5$ to 0.8$)$ \\
\hline 12 months versus baseline & $33(61)$ & $-0.5(6.4)$ & $-0.7(-2.4$ to 1.0$)$ \\
\hline ATP versus STP, difference at baseline & - & - & $1.8(-9.4$ to 13.1$)$ \\
\hline ATP versus STP, difference at follow-up at 6 months & - & - & $0.3(-10.9$ to 11.6$)$ \\
\hline ATP versus STP, difference at follow-up at 12 months & - & - & $0.3(-11$ to 11.6$)$ \\
\hline $\begin{array}{l}\text { ATP versus STP, difference in follow-up at } 6 \text { months versus } \\
\text { baseline differences }\end{array}$ & - & - & $-1.5(-3.7$ to 0.6$)$ \\
\hline $\begin{array}{l}\text { ATP versus STP, difference in follow-up at } 12 \text { months versus } \\
\text { baseline differences }\end{array}$ & - & - & $-1.5(-3.9$ to 0.9$)$ \\
\hline
\end{tabular}

${ }^{\text {a}}$ PHQ-9: Patient Health Questionnaire-9; range 0-27, higher is more depressed.

${ }^{\mathrm{b}}$ From mixed-effects linear regression models adjusted for study site, consulting psychiatrist, and language of the interview, as well as clustering due to patient and primary care physician.

${ }^{\mathrm{c}}$ ATP: asynchronous telepsychiatry.

${ }^{\mathrm{d}}$ Not available.

${ }^{\text {e}}$ STP: synchronous telepsychiatry.

The results of the secondary analysis (Multimedia Appendix 1, Tables S3-S5) parallel those of the primary analysis, with ATP and STP groups maintaining improvements in both CGI and GAF at 18 and 24 months as compared with baseline and showed no significant interactions between the intervention arm and follow-up times. Sensitivity analyses adjusted for baseline score severity confirmed the results of the primary analyses.

\section{Treatment Adherence, Data Availability, and Unanticipated Events}

Adverse or unanticipated events during the trial were reported to the IRB and the DSMB and included 2 patient deaths from unrelated medical complications and 2 patients who threatened self-harm. Both patients who threatened self-harm were urgently contacted by study psychiatrists to make clinical decisions on their follow-up care. The DSMB determined that neither event was study related. A total of 2 participants were randomized to
ATP but completed the STP procedures after the baseline. One of these patients, who was urgently seen in person because of suicidal ideation, requested to continue seeing a psychiatrist through STP and was switched from ATP to STP. Another patient was misscheduled from ATP to STP and continued the study in the STP group. During the course of the study, for administrative reasons, the study psychiatrists failed to return notes for 10 completed visits (8 ATP and 2 STP).

\section{Discussion}

\section{Principal Findings}

This study is the first randomized controlled clinical trial to compare STP with ATP in primary care. It has a number of strengths, including being conducted in primary care practice settings using a collaborative care model ( 3 sites, including 1 rural site) with a diverse patient sample of English- and 
Spanish-speaking patients and a much longer follow-up period than most psychiatric clinical trials. Clinical outcomes were assessed using both clinician and patient self-reported ratings and included both mental health as well as broader measures of health status. A large number of PCPs continued to refer patients to the study for 4 years. The referred patients were typically individuals with mild to moderate anxiety and depression who were mainly treated by PCPs and often did not receive care from a psychiatrist.

At both 12 and 24 months of follow-up, we found that ATP was not superior to STP in improving patient outcomes. However, both ATP and STP patients showed improvements from baseline in 2 separate clinician-rated outcomes at 12-month (of about 1 point for functional impairment on the CGI and 5 points on symptom severity for the GAF) and 24-month follow-up (of about 1 point for CGI and 8 points for GAF). The magnitude of these improvements is similar to those found in recent clinical trials on the effect of nonpharmacological interventions on patient outcomes $[45,49,50]$. Studies suggest that the minimum clinically meaningful change on the CGI is a 1-point change $[49,50]$, and we have not found similar studies using the CGI outcome for follow-up periods longer than 6 months. A 1-point improvement in our relatively mildly ill population, as we found, is arguably even more clinically significant than in a population that was more severely ill on average at baseline. The findings of an improvement of 8 points on the GAF are similar to long-term therapies in comparable clinical trials [51].

This study was not a noninferiority trial; the sponsor hoped to demonstrate the superiority of ATP. The results did not support the primary hypothesis that ATP promotes more improvement than STP. For clinician ratings, both the ATP and STP arms improved at similar rates throughout the trial, with no significant differences in improvements between the 2 arms. Although not supporting our primary hypothesis, this is still a clinically important result. The standardized implementation of ATP across several primary care settings for a long follow-up period, with improved clinical outcomes at 1 year and 2 years, supports the feasibility of the ATP model of care to treat depression and anxiety using a psychiatric consultation model in patients treated in primary care. This treatment option may be particularly important after the COVID-19 pandemic.

The mental health care system has been significantly affected by the COVID-19 pandemic, with what has been described as a follow-on mental health pandemic [52]. Both the World Health Organization [53] and the Centers for Disease Control [54] have published reports describing greater community levels of depression, anxiety, substance use, domestic violence, sexual abuse and related trauma, and likely suicides. Mental health professionals are required to develop new telepsychiatry protocols and digital systems to help patients who stay at home [55], whereas the number of STP consultations nationwide has dramatically escalated. ATP can provide an innovative solution to treat people in their homes as part of the COVID-19 pandemic response, and the ATP collaborative care model leverages the expertise of psychiatrists to oversee the treatment of larger numbers of patients. In 2020, we continued testing ATP methods to treat patients in their homes and nursing homes. We plan to conduct an ATP homecare trial treating psychiatric disorders in patients who have been severely affected by COVID-19.

The results of this trial have several other implications beyond COVID-19 for broadening access to psychiatric care within underserved populations and across different countries and language groups as well as in reaching new care settings.

First, the results establish that this type of consultation is worth considering as a care option in any collaborative care program. We believe that this large trial of patients treated with ATP for up to 2 years provides evidence that should enable insurers and payers to support payment for ATP consultations. We are already conducting a similar study in skilled nursing facilities, and early engagement and feedback is positive [34]. We see many more opportunities for ATP consultations for assessment and monitoring to occur not only in primary care and remotely in patients' homes but also in pediatric and geriatric psychiatry and correctional environments and for a range of specific psychiatric assessments, such as before bariatric or transplant surgery.

Second, $19.6 \%(36 / 184)$ of the patients enrolled in this trial were Hispanic. It is evident that ATP with a Spanish-speaking interviewer can improve access to psychiatric care for patients who speak only Spanish. This language-matching option provides an important opportunity to increase the availability of mental health care for patients from many language groups within the United States and around the world. We are developing automated language transcription and translation systems to enable this option.

Third, ATP consultations should improve access to psychiatrists. Psychiatrists are in short supply, especially in the primary care environment, and ATP consultations for monitoring and treating patients is an approach to diminishing the impending shortage of these specialists. The 4 treating psychiatrists in this trial did most of their consultations from their usual office environment and were often able to complete their ATP consultations in downtime when other patients had canceled. The psychiatrists saw this as a major practical advantage of ATP, as it increased their work efficiency while guiding PCPs more quickly than typical in-person or STP consultations. We are currently undertaking an economic evaluation of trial results. Additional data from this trial will be used to evaluate patient and provider satisfaction, cost-effectiveness, and PCP adherence with the psychiatrist's recommendations and investigate diagnosis-specific clinical outcomes in future publications.

\section{Limitations}

There were some limitations to this study. We anticipated a $25 \%$ dropout rate for the 2-year study. However, of the 160 patients who completed baseline, 67 (41.9\%; 31 ATP and 36 STP) withdrew from the study at either 6 or 12 months, and only 47 (29.4\%) patients completed the study as enrolled, despite regular communication from the research team. This is not unusual, as dropout rates in long-term randomized trials for depression in primary care range from $25 \%$ to $52 \%$ at 1 year [56] and higher for longer studies [57]. Although our dropout rate was higher than initially anticipated, it was comparable with or even less than that of other similar longitudinal trials. 
In a study, only $43.9 \%$ of participants had data collected at 12 months [54], whereas our study retained $58.1 \%$ of participants (93/160) at 12 months. In another study, $51 \%$ of participants completed their 12-month checkup, and 19.6\% dropped out of the intervention group with less than 4 weeks of participation [55]. Of the $41.9 \%(67 / 160)$ of patients who completed baseline interviews and withdrew from our study in the first year, some patients reported that they dropped out because they felt good and needed no further treatment, and others because they saw no improvement. Others dropped out because they moved, whereas cessation of coverage by an insurer midway through the trial forced a number of patients $(n=18)$ to seek care elsewhere. Patients were recruited from primary care in Northern California, primarily experiencing depression or mood disorders. Although this population is very socially and ethnically diverse, with more than 100 languages spoken in the Sacramento region, the generalizability of our findings to other settings and types of patients is unknown. Due to the nature of the intervention, blinding for either patients or clinicians was not feasible. Finally, relatively high dropout rates in both arms may have skewed follow-up outcomes if there is a relationship between the propensity of a data point to be missing and its values, although it is difficult to predict the direction of the bias.

\section{Conclusions}

Although this clinical trial with a 2-year follow-up period does not provide evidence for the superiority of ATP in improving clinical outcomes in comparison with STP, there was a significant improvement in primary outcomes in patients treated with either ATP or STP. Both ATP and STP promise to be important components of collaborative care systems that can increase access to psychiatrists; while ATP, because of its scalability, can improve the efficiency of psychiatric care and help alleviate the shortage of psychiatrists. The bilingual utility of ATP also shows its potential to reach non-English-speaking populations in the United States. Further research could examine the effectiveness of ATP with additional populations, settings, and cost considerations.

\section{Acknowledgments}

This work was supported by the Agency for Healthcare Research and Quality through award HS21477 (to PMY). Data management for this project was supported by the National Center for Advancing Translational Sciences, National Institutes of Health, through the award UL1 TR001860. The authors thank the members of the Data Safety Monitoring Board, D Dierks, MD; B Durbin-Johnson, $\mathrm{PhD}$; and $\mathrm{E}$ Ochoa, $\mathrm{MD}$, and the primary care practitioners who referred their patients to our study and the participants of the study. A Odor, MD, an original investigator on the trial, is deceased.

\section{Authors' Contributions}

PMY, MBP, and AMI conceptualized the study. PMY, MBP, and AMI drafted the original draft. AMI designed the analytical plan. AMI, AF, and JRF conducted the analyses. All authors reviewed and approved the final manuscript.

\section{Conflicts of Interest}

The authors report no conflicting financial relationships with commercial interests except PMY, who received royalties from the American Psychiatric Association Press. JS is Chief Medical Officer for AccessCare, a provider of telemental health services, and has received royalties from the American Psychiatric Association Press and Springer Press. AMI has received honoraria for reviewing activities from Elsevier. SRC provided consultation services for Advanced Clinical, University of Wisconsin, Madison, and Orbit Health Telepsychiatry; he has also provided speaking services for North American Center for Continuing Medical Education, LLC; Scholastic Expeditions; Arizona Psychiatric Society; and Guidewell Innovation. He has affiliations with University of California, San Francisco; University of California, Davis; and Stanford University School of Medicine.

\section{Multimedia Appendix 1}

Additional data and materials.

[DOCX File, 627 KB-Multimedia Appendix 1]

\section{Multimedia Appendix 2}

CONSORT-eHEALTH checklist (V 1.6.1).

[PDF File (Adobe PDF File), 1154 KB-Multimedia Appendix 2]

\section{References}

1. Bashshur RL, Shannon GW, Bashshur N, Yellowlees PM. The empirical evidence for telemedicine interventions in mental disorders. Telemed J E Health 2016 Feb;22(2):87-113 [FREE Full text] [doi: 10.1089/tmj.2015.0206] [Medline: 26624248]

2. Hilty DM, Ferrer DC, Parish MB, Johnston B, Callahan EJ, Yellowlees PM. The effectiveness of telemental health: a 2013 review. Telemed J E Health 2013 Jun;19(6):444-454 [FREE Full text] [doi: 10.1089/tmj.2013.0075] [Medline: 23697504]

3. Elliott T, Yopes MC. Direct-to-consumer telemedicine. J Allergy Clin Immunol Pract 2019 Nov;7(8):2546-2552. [doi: 10.1016/j.jaip.2019.06.027] [Medline: $\underline{31706486]}$ 
4. Shore JH, Schneck CD, Mishkind MC. Telepsychiatry and the coronavirus disease 2019 pandemic-current and future outcomes of the rapid virtualization of psychiatric care. JAMA Psychiatry 2020 Dec 1;77(12):1211-1212. [doi: $\underline{10.1001 / j a m a p s y c h i a t r y .2020 .1643}$ ] [Medline: $\underline{\text { 32391861] }}$

5. Psychiatrists Use of Telepsychiatry During COVID-19 Public Health Emergency: Policy Recommendations. American Psychiatric Association. 2020. URL: https://www.psychiatry.org/psychiatrists/practice/telepsychiatry/blog/ apa-resources-on-telepsychiatry-and-covid-19 [accessed 2021-06-22]

6. Monthly Telehealth Regional Tracker. Fair Health. Amazon News. URL: https://s3.amazonaws.com/media2.fairhealth.org/ infographic/telehealth/dec-2020-national-telehealth.pdf [accessed 2021-06-22]

7. Ambulatory Care Use and Physician Office Visits. National Center for Health Statistics. 2020. URL: https://www.cdc.gov/ nchs/fastats/physician-visits.htm [accessed 2021-06-22]

8. Yellowlees P, Shore J. Telepsychiatry and Health Technologies: a Guide for Mental Health Professionals. Washington, DC: The American Psychiatric Association; 2018.

9. Shore JH, Yellowlees P, Caudill R, Johnston B, Turvey C, Mishkind M, et al. Best practices in videoconferencing-based telemental health april 2018. Telemed J E Health 2018 Nov;24(11):827-832. [doi: 10.1089/tmj.2018.0237] [Medline: 30358514]

10. Brooks E, Turvey C, Augusterfer EF. Provider barriers to telemental health: obstacles overcome, obstacles remaining. Telemed J E Health 2013 Jun;19(6):433-437. [doi: 10.1089/tmj.2013.0068] [Medline: 23590176]

11. Cowan K, McKean A, Gentry M, Hilty D. Barriers to use of telepsychiatry: clinicians as gatekeepers. Mayo Clin Proc 2019 Dec;94(12):2510-2523. [doi: 10.1016/j.mayocp.2019.04.018] [Medline: 31806104]

12. Nesbitt T, Yellowlees P, Hogarth M, Hilty D. Quality Through Collaboration: The Future of Rural Health. Washington DC: The National Academies Press; 2005.

13. Collins K, Nicolson P, Bowns I, Walters S. General practitioners' perceptions of store-and-forward teledermatology. J Telemed Telecare 2000;6(1):50-53. [doi: 10.1258/1357633001933844] [Medline: 10824392]

14. Chan S, Li L, Torous J, Gratzer D, Yellowlees PM. Review of use of asynchronous technologies incorporated in mental health care. Curr Psychiatry Rep 2018 Aug 28;20(10):85-11. [doi: 10.1007/s11920-018-0954-3] [Medline: 30155593]

15. Thrall JH. Teleradiology. Part I. History and clinical applications. Radiology 2007 Jun;243(3):613-617. [doi: 10.1148/radiol.2433070350] [Medline: 17517922]

16. High WA, Houston MS, Calobrisi SD, Drage LA, McEvoy MT. Assessment of the accuracy of low-cost store-and-forward teledermatology consultation. J Am Acad Dermatol 2000 May;42(5 Pt 1):776-783. [doi: 10.1067/mjd.2000.104519] [Medline: 10775853]

17. Rashid E, Ishtiaq O, Gilani S, Zafar A. Comparison of store and forward method of teledermatology with face-to-face consultation. J Ayub Med Coll Abbottabad 2003;15(2):34-36. [Medline: 14552246]

18. Rotvold G, Knarvik U, Johansen MA, Fossen K. Telemedicine screening for diabetic retinopathy: staff and patient satisfaction. J Telemed Telecare 2003;9(2):109-113. [doi: 10.1258/135763303321327984] [Medline: 12699582]

19. Hooper GS, Yellowlees P, Marwick TH, Currie PJ, Bidstrup BP. Telehealth and the diagnosis and management of cardiac disease. J Telemed Telecare 2001;7(5):249-256. [doi: 10.1258/1357633011936471] [Medline: 11571078]

20. Mahnke CB, Mulreany MP, Inafuku J, Abbas M, Feingold B, Paolillo JA. Utility of store-and-forward pediatric telecardiology evaluation in distinguishing normal from pathologic pediatric heart sounds. Clin Pediatr (Phila) 2008 Nov;47(9):919-925. [doi: 10.1177/0009922808320596] [Medline: 18626106$]$

21. Williams S, Henricks WH, Becich MJ, Toscano M, Carter AB. Telepathology for patient care: what am I getting myself into? Adv Anat Pathol 2010 Mar;17(2):130-149. [doi: 10.1097/PAP.0b013e3181cfb788] [Medline: 20179435]

22. Giansanti D, Castrichella L, Giovagnoli MR. Telepathology requires specific training for the technician in the biomedical laboratory. Telemed J E Health 2008 Oct;14(8):801-807. [doi: 10.1089/tmj.2007.0130] [Medline: 18954250]

23. Richardson CG, Slemon A, Gadermann A, McAuliffe C, Thomson K, Daly Z, et al. Use of asynchronous virtual mental health resources for covid-19 pandemic-related stress among the general population in Canada: cross-sectional survey study. J Med Internet Res 2020 Dec 30;22(12):e24868 [FREE Full text] [doi: 10.2196/24868] [Medline: 33315583]

24. Baumeister H, Reichler L, Munzinger M, Lin J. The impact of guidance on internet-based mental health interventions a systematic review. Internet Interv 2014 Oct;1(4):205-215. [doi: 10.1016/j.invent.2014.08.003]

25. Hull TD, Mahan K. A study of asynchronous mobile-enabled SMS text psychotherapy. Telemed J E Health 2017 Mar;23(3):240-247. [doi: 10.1089/tmj.2016.0114] [Medline: 27797646]

26. Melmed A. Chat with a doctor: using asynchronous virtual care access for on-demand physician advice. Iproc 2017 Sep 22;3(1):e18 [FREE Full text] [doi: 10.2196/iproc.8451]

27. Myers K, Cummings JR, Zima B, Oberleitner R, Roth D, Merry SM, et al. Advances in asynchronous telehealth technologies to improve access and quality of mental health care for children and adolescents. J Technol Behav Sci 2018 Apr 6;3(2):87-106. [doi: 10.1007/s41347-018-0055-5]

28. Balasinorwala VP, Shah NB, Chatterjee SD, Kale VP, Matcheswalla YA. Asynchronous telepsychiatry in maharashtra, India: study of feasibility and referral pattern. Indian J Psychol Med 2014 Jul 1;36(3):299-301 [FREE Full text] [doi: 10.4103/0253-7176.135384] [Medline: 25035555] 
29. Odor A, Yellowlees P, Hilty D, Parish MB, Nafiz N, Iosif A. PsychVACS: a system for asynchronous telepsychiatry. Telemed J E Health 2011 May;17(4):299-303. [doi: 10.1089/tmj.2010.0159] [Medline: 21457014]

30. Yellowlees PM, Odor A, Parish MB, Iosif A, Haught K, Hilty D. A feasibility study of the use of asynchronous telepsychiatry for psychiatric consultations. Psychiatr Serv 2010 Aug;61(8):838-840. [doi: 10.1176/ps.2010.61.8.838] [Medline: 20675845]

31. Yellowlees P, Burke Parish M, González A, Chan S, Hilty D, Iosif A, et al. Asynchronous telepsychiatry: a component of stepped integrated care. Telemed J E Health 2018 May;24(5):375-378 [FREE Full text] [doi: 10.1089/tmj.2017.0103] [Medline: 29024612]

32. Yellowlees PM, Odor A, Parish MB. Cross-lingual asynchronous telepsychiatry: disruptive innovation? Psychiatr Serv 2012 Sep 1;63(9):945. [doi: 10.1176/appi.ps.2012op945] [Medline: 22949020]

33. Yellowlees PM, Odor A, Parish MB, Iosif A, Haught K, Hilty D. A feasibility study of the use of asynchronous telepsychiatry for psychiatric consultations. Psychiatr Serv 2010 Aug;61(8):838-840. [doi: 10.1176/ps.2010.61.8.838] [Medline: 20675845]

34. Xiong GL, Iosif A, Godwin HT, Khan M, Parish MB, Yellowlees P, et al. A pilot randomized trial of asynchronous and synchronous telepsychiatry in skilled nursing facilities. J Am Med Dir Assoc 2018 May;19(5):461-462. [doi: 10.1016/j.jamda.2018.02.007] [Medline: 29704928]

35. Butler TN, Yellowlees P. Cost analysis of store-and-forward telepsychiatry as a consultation model for primary care. Telemed J E Health 2012 Jan;18(1):74-77. [doi: 10.1089/tmj.2011.0086] [Medline: 22085113]

36. Kroenke K, Spitzer RL. The PHQ-9: a new depression diagnostic and severity measure. Psych Annals 2002 Sep;32(9):509-515. [doi: 10.3928/0048-5713-20020901-06]

37. First M. Structured clinical interview for the DSM (SCID). Clin Psychol 2014:1-6.

38. Parish MB, Gonzalez A, Hilty D, Chan S, Xiong G, Scher L, et al. Asynchronous telepsychiatry interviewer training recommendations: a model for interdisciplinary, integrated behavioral health care. Telemed J E Health 2021 Jan 12:- epub ahead of print. [doi: 10.1089/tmj.2020.0076] [Medline: 33434453]

39. Guy W. Clinical Global Impressions: ECDEU Assessment Manual for Psychopharmacology. Rockville, MD: US Department of Health, Education, and Welfare, Public Health Service, Alcohol, Drug Abuse, and Mental Health Administration, NIMH Psychopharmacology Research Branch, Division of Extramural Research Programs; 1976.

40. Hall RC. Global assessment of functioning. Psychosomatics 1995 May;36(3):267-275. [doi: 10.1016/s0033-3182(95)71666-8]

41. Berk M, Ng F, Dodd S, Callaly T, Campbell S, Bernardo M, et al. The validity of the CGI severity and improvement scales as measures of clinical effectiveness suitable for routine clinical use. J Eval Clin Pract 2008 Dec;14(6):979-983. [doi: 10.1111/j.1365-2753.2007.00921.x] [Medline: 18462279]

42. Kørner A, Lauritzen L, Abelskov K, Gulmann NC, Brodersen A, Wedervang-Jensen T, et al. Rating scales for depression in the elderly: external and internal validity. J Clin Psychiatry 2007 Mar 15;68(3):384-389. [doi: 10.4088/jcp.v68n0305] [Medline: 17388707 ]

43. Gandek B, Ware JE, Aaronson NK, Apolone G, Bjorner JB, Brazier JE, et al. Cross-validation of item selection and scoring for the SF-12 health survey in nine countries. J Clin Epidemio 1998 Nov;51(11):1171-1178. [doi:

10.1016/s0895-4356(98)00109-7]

44. Kroenke K, Spitzer RL, Williams JB. The PHQ-9: validity of a brief depression severity measure. J Gen Intern Med 2001 Sep;16(9):606-613 [FREE Full text] [doi: 10.1046/j.1525-1497.2001.016009606.x] [Medline: 11556941]

45. Dunner DL, Aaronson ST, Sackeim HA, Janicak PG, Carpenter LL, Boyadjis T, et al. A multisite, naturalistic, observational study of transcranial magnetic stimulation for patients with pharmacoresistant major depressive disorder. J Clin Psychiatry 2014 Sep 16;75(12):1394-1401. [doi: 10.4088/jcp.13m08977]

46. Müller-Nordhorn J, Roll S, Willich SN. Comparison of the short form (SF)-12 health status instrument with the SF-36 in patients with coronary heart disease. Heart 2004 May;90(5):523-527 [FREE Full text] [doi: 10.1136/hrt.2003.013995] [Medline: 15084550 ]

47. Laird NM, Ware JH. Random-effects models for longitudinal data. Biometrics 1982 Dec;38(4):963-974. [Medline: 7168798]

48. SAS/STAT 9.4. 2013. URL: https://www.sas.com [accessed 2021-06-22]

49. Roux P, Brunet-Gouet E, Ehrminger M, Aouizerate B, Aubin V, Azorin JM, FondaMental Advanced Centers of Expertise in Bipolar Disorders (FACE-BD) Collaborators, et al. Minimum clinically important differences for the functioning assessment short test and a battery of neuropsychological tests in bipolar disorders: results from the FACE-BD cohort. Epidemiol Psychiatr Sci 2020 Jul 20;29:e144 [FREE Full text] [doi: 10.1017/S2045796020000566] [Medline: 32684190]

50. Mischoulon D, Hylek L, Yeung AS, Clain AJ, Baer L, Cusin C, et al. Randomized, proof-of-concept trial of low dose naltrexone for patients with breakthrough symptoms of major depressive disorder on antidepressants. J Affect Disord 2017 Jan 15;208:6-14. [doi: 10.1016/j.jad.2016.08.029] [Medline: 27736689]

51. Lorentzen S, Ruud T, Fjeldstad A, Høglend P. Comparison of short- and long-term dynamic group psychotherapy: randomised clinical trial. Br J Psychiatry 2013 Sep 2;203(3):280-287. [doi: 10.1192/bjp.bp.112.113688] [Medline: 24029539]

52. Xiang Y, Yang Y, Li W, Zhang L, Zhang Q, Cheung T, et al. Timely mental health care for the 2019 novel coronavirus outbreak is urgently needed. The Lancet Psychiatry 2020 Mar;7(3):228-229. [doi: 10.1016/s2215-0366(20)30046-8]

53. Mental Health and Covid-19. World Health Organization. 2020. URL: https://www.who.int/teams/ mental-health-and-substance-use/covid-19 [accessed 2021-06-21] 
54. Stephenson J. CDS report reveals 'considerably elevated' mental health toll from covid-19 stresses. JAMA Health Forum 2020 Aug 25;1(8):e201078. [doi: 10.1001/jamahealthforum.2020.1078]

55. Yellowlees P, Nakagawa K, Pakyurek M, Hanson A, Elder J, Kales HC. Rapid conversion of an outpatient psychiatric clinic to a 100\% virtual telepsychiatry clinic in response to covid-19. Psychiatr Serv 2020 Jul 1;71(7):749-752. [doi: 10.1176/appi.ps.202000230] [Medline: 32460683]

56. Wilkinson P, Izmeth Z. Continuation and maintenance treatments for depression in older people. Cochrane Database Syst Rev 2016 Sep 9;9:CD006727 [FREE Full text] [doi: 10.1002/14651858.CD006727.pub3] [Medline: 27609183]

57. Schulberg HC, Coulehan JL, Block MR, Scott CP, Imber SD, Perel JM. Strategies for evaluating treatments for major depression in primary care patients. Gen Hosp Psychiatry 1991 Jan;13(1):9-18. [doi: 10.1016/0163-8343(91)90004-g] [Medline: 1993523]

\author{
Abbreviations \\ ATP: asynchronous telepsychiatry \\ CGI: Clinical Global Impression \\ DSMB: data and safety monitoring board \\ EMR: electronic medical records \\ GAF: Global Assessment of Functioning \\ IRB: institutional review board \\ MHS-12: 12 -Item Short-Form Health Survey Mental Health Summary \\ PCP: primary care physician \\ PHQ-9: Patient Health Questionnaire-9 \\ PHS-12: 12-Item Short-Form Health Survey Physical Health Summary \\ SCID: Structured Clinical Interview for the Diagnostic Statistical Manual \\ STP: synchronous telepsychiatry \\ UCD: University of California Davis
}

\author{
Edited by G Eysenbach; submitted 03.09.20; peer-reviewed by R Bailey, P Chand, MW Haun, S Jyothi, A Khoja, A Serrano-Blanco; \\ comments to author 19.11.20; revised version received 26.03.21; accepted 16.05.21; published 20.07.21 \\ Please cite as: \\ Yellowlees PM, Parish MB, Gonzalez AD, Chan SR, Hilty DM, Yoo BK, Leigh JP, McCarron RM, Scher LM, Sciolla AF, Shore J, \\ Xiong G, Soltero KM, Fisher A, Fine JR, Bannister J, Iosif AM \\ Clinical Outcomes of Asynchronous Versus Synchronous Telepsychiatry in Primary Care: Randomized Controlled Trial \\ J Med Internet Res 2021;23(7):e24047 \\ URL: https://www.jmir.org/2021/7/e24047 \\ doi: 10.2196/24047 \\ PMID: 33993104
}

CPeter M Yellowlees, Michelle Burke Parish, Alvaro D Gonzalez, Steven R Chan, Donald M Hilty, Byung-Kwang Yoo, J Paul Leigh, Robert M McCarron, Lorin M Scher, Andres F Sciolla, Jay Shore, Glen Xiong, Katherine M Soltero, Alice Fisher, Jeffrey R Fine, Jennifer Bannister, Ana-Maria Iosif. Originally published in the Journal of Medical Internet Research (https://www.jmir.org), 20.07.2021. This is an open-access article distributed under the terms of the Creative Commons Attribution License (https://creativecommons.org/licenses/by/4.0/), which permits unrestricted use, distribution, and reproduction in any medium, provided the original work, first published in the Journal of Medical Internet Research, is properly cited. The complete bibliographic information, a link to the original publication on https://www.jmir.org/, as well as this copyright and license information must be included. 